\title{
EL CONCEJO DE PEÑAFIEL. GOBIERNO Y SOCIEDAD EN UNA VILLA VALLISOLETANA EN LA EDAD MEDIA
}

\author{
Víctor Muñoz Gómez
}

\section{RESUMEN}

Se propone una análisis diacrónico del concejo de la villa vallisoletana de Peñafiel, atendiendo a las transformaciones formales de este institución de gobierno desde sus orígenes en el siglo XII hasta alcanzar su forma más o menos definitivamente a finales de la Edad Media. El desarrollo institucional presentado remite, en último término, a las dinámicas de orden político y social vividas en la villa durante estos siglos, extensibles a otras villas señoriales de la Corona de Castilla, en lo tocante a la oligarquización del poder concejil y la progresiva intromisión de la autoridad señorial en el ámbito municipal.

Palabras claves: Gobierno, Sociedad, Concejo, Villa, Oligarquización, Autoridad señorial, Peñafiel, Castilla.

\begin{abstract}
We propose a diachronic analysis of the urban council of Peñafiel, a castilian town in Valladolid, attending to formal transformations of this government institution from its origins in the XIIth century to the end of the Middle Ages, when it reached its more or less definitive structure. In last term, institutional development here presented refers to the dynamics of social and political order experienced in this town during these centuries, offering a typical example of seignorial towns of the Crown of Castile, in order to observe the phenomena of counciliar power's oligarchization and progressive interference of the seignorial authority into municipal sphere.
\end{abstract}

Keywords: Government, Society, Urban council, Town, Oligarchization, Seignorial Authority, Peñafiel, Castile.

Fecha de recepción: 16 de noviembre de 2009. Fecha de aceptación: 20 de enero de 2010.

1 Universidad de Valladolid. Email: vgm1981@gmail.com. 
La vitalidad que en los tiempos presentes ha alcanzado Peñafiel, en el corazón de la Ribera del Duero en la provincia de Valladolid, se halla, como es bien sabido, directamente relacionados con el sobresaliente desarrollo vitivinícola de su comarca en los últimos años. El dinamismo de la localidad, no obstante, no se limita al extraordinario potencial de este sector. Precisamente, uno de sus más destacados activos para el progreso de la villa es su rico patrimonio monumental, del que merecen la pena destacar su castillo, la plaza del Coso o la iglesia mudéjar del antiguo convento de San Juan y San Pablo, entre otros edificios.

Este conjunto histórico-artístico nos remite, en efecto, a la Edad Media, época en la que Peñafiel alcanzó un esplendor dentro de las tierras de Castilla y León, y del conjunto de la Corona de Castilla, acaso no recuperados hasta nuestros días, unido a nombres tan señeros como el de don Juan Manuel, ilustre pariente de los reyes de Castilla e inolvidable escritor, el del príncipe de Viana o el de don Pedro Girón, maestre de Calatrava. Aunque no han faltado las investigaciones que han indagado en el pasado de la villa en esta época, sobre todo desde el punto de vista histórico-jurídico, lo cierto es que nuestros conocimientos sobre la evolución de la villa y su entorno en los siglos medievales es muy limitado. Ello se ha debido, en buena medida, a la pérdida de los fondos antiguos del archivo municipal de la localidad y a la posterior disgregación de aquellos documentos que se salvaron de la destrucción. Sea como fuere, no es imposible arrojar luz sobre determinados aspectos del pasado medieval de Peñafiel a partir de un buen número de fuentes escritas dispersas en distintos archivos estatales y eclesiásticos, de los vestigios arqueológicos existentes y de una interesante y dispar bibliografía.

El objeto de este estudio es llamar la atención sobre uno de estos temas: la estructura del concejo de la villa y tierra de Peñafiel, el órgano de gobierno de la misma. Este asunto no es, en principio, del todo desconocido, a partir del análisis realizado de los fueros de la villa ${ }^{2}$ y, sobre todo, de las famosas ordenanzas de don Juan Manuel de $1345^{3}$, si bien se limita a ciertas imágenes fijas sobre la forma y composición del concejo en momentos muy concretos. La relevancia que alcanzó Peñafiel fundamentalmente durante la Baja Edad Media, el hecho de que nos encontremos ante un ejemplo espléndido de lugar de señorío - en general menos conocidos que las villas y ciudades de realengo de la Castilla medieval - y la localización de referencias abundantes y de alto valor informativo sobre el concejo peñafielense en un arco cronológico que va de los siglos XII-XIII al siglo $\mathrm{XV}$, hacen perfectamente procedente la profundización en este objeto de estudio en dos

\footnotetext{
* Este trabajo ha sido galardonado con el Primer Premio de los "Premios Argaya para Jóvenes Creadores, año 2009”, convocados y otorgados por la Diputación de Valladolid, en su modalidad de Monografías. Se publica aquí la versión del mismo que fue objeto de este reconocimiento.

2 GONZÁLEZ DÍEZ, E., El régimen foral vallisoletano. Una perspectiva de análisis organizativo del territorio, Valladolid, 1986; RODRÍGUEZ FERNÁNDEZ, J., "Los fueros de Peñafiel (Valladolid), y su notación histórica", Anuario de Estudios Medievales, 17, 1987, pp. 35-42, donde se sintetiza la labor realizada en esta línea de investigación.

3 RIVERA MANESCAU, S., Ordenanzas dadas a su villa de Peñafiel por D. Juan, hijo del Infante D. Manuel", Revista Histórica, 8, 1925, pp. 167-192, y 9, 1926, pp. 193-206; KINKADE, R., Ordenamientos dados a la villa de Peñafiel, 10 de abril de 1345. A reconstruction of the Manuscript Text with an Introduction and Annotated English Translation, Madison, 1996.
} 
sentidos: el enriquecimiento de la memoria histórica local de Peñafiel, como patrimonio inmaterial del municipio, y la contribución general a los estudios medievales de temática urbana y territorial de la Corona de Castilla.

Así, lo que proponemos en las siguientes páginas es una observación diacrónica de la institución concejil de Peñafiel y sus transformaciones desde la "repoblación" y organización de la villa hasta los inicios de la Edad Moderna. El recorrido que se plantea, desde el "concejo abierto" realengo de la "Extremadura castellano-leonesa" plenomedieval hasta el peculiar diseño de "concejo cerrado" mediatizado por la presencia señorial que se operó en esta villa vallisoletana al final de la Edad Media, nos coloca ante las diferentes dinámicas políticas y sociales que afectaron a las formas de articular el gobierno urbano tanto en el contexto general castellano como en el más concreto marco local.

\section{PEÑAFIEL Y SU TIERRA EN LA EDAD MEDIA}

La villa de Peñafiel tuvo su origen durante los siglos plenomedievales, al calor de la expansión de la monarquía de León y Castilla tras el derrumbe del califato de Córdoba, a comienzo del siglo XI, por la llamada "Extremadura castellano-leonesa", entre el Duero y el Sistema Central, y aún más al sur, por el reino de Toledo y toda la Transierra hacia el Tajo. La organización de los territorio al sur del Duero protagonizados por los poderes castellano-leoneses durante los siglos plenomedievales dio lugar a que Peñafiel, que había surgido como uno de los castillos de la frontera dominados por el conde de Monzón frente al califato de Córdoba a mediados del siglo X, situada en la estratégica confluencia de los ríos Duratón y Duero, pasase a convertirse, entre el final del siglo XI y a lo largo del siglo XII, en la villa cabecera de una de las "comunidades de Villa y Tierra" que articulaban este espacio de la "Extremadura", dependiendo directamente de la autoridad del Rey ${ }^{4}$.

Este modelo de vertebración territorial de "comunidad de Villa y Tierra" suponía la ordenación bajo la autoridad jurisdiccional superior de un centro de carácter urbano - y de las instituciones rectoras de éste, por tanto- de vastos espacios en inicio escasamente poblados, recorridos de un diverso número de aldeas, en términos jurídicoinstitucionales, políticos, sociales, económicos y militares. Esta fórmula de desarrollo del fenómeno urbano, combinado con una poderosa dimensión de organización territorial, resultó tan exitosa como para extenderse por toda la Corona de Castilla hasta el final de la Edad Media, tanto en las tierras del sur que iban siendo conquistadas a los

4 Sobre este proceso histórico y las “comunidades de Villa y Tierra”, entre otros, MARTÍNEZ DÍEZ, G., Las Comunidades de Villa y Tierra de la Extremadura Castellana: estudios histórico-geográfico, Madrid, 1983, pp. 9-47 y, más en concreto sobre Peñafiel, pp. 385-389; VILLAR GARCÍA, L. M., La Extremadura castellanoleonesa: guerreros, clérigos y campesinos (711-1252), Valladolid, 1986; MARTÍNEZ LLORENTE, F. J., Régimen jurídico de la Extremadura castellana medieval. Las Comunidades de Villa y Tierra (s. X-XIV), Valladolid, 1990,pp. 38-57; y MONSALVO ANTÓN, J. Ma ., "Frontera pionera, monarquía en expansión y formación de los concejos de villa y tierra. Relaciones de poder en el realengo concejil entre el Duero y el Tajo (c.1072- c. 1222)", Arqueología y Territorio Medieval, 10.2, 2003, 45-126. 
musulmanes como en las áreas interiores de la monarquía de Castilla y León entre el Cantábrico y el Duero5.

A partir de que, entre 1191 y 1207-1219, los términos bajo la jurisdicción de Peñafiel quedaran más o menos definidos ${ }^{6}$ : la villa y tierra de Peñafiel ocupó una extensión de unos $370 \mathrm{kms}^{2}{ }^{2}$, en los que se localizaban, además de la propia villa, hasta veintitrés núcleos de población más, entre los quince hoy supervivientes y otros ocho despoblados, tal y como pudo reconstruir G. Martínez Díaz?

Ya adelantábamos la condición señorial de la villa de Peñafiel durante buena parte de la Edad Media. En efecto, aunque ésta había nacido como un lugar de realengo, desde el final del siglo XII comenzó a formar parte de los patrimonios señoriales de diferentes miembros de la familia real. De hecho, el esquema de la señorialización de Peñafiel encaja en el dibujado por J. Ma . Monsalvo para el conjunto de las villas extremaduranas que, a partir de los siglos XIII-XIV pasaron a convertirse en señoríos, primero como dominios de diferentes parientes reales hasta que, tras el final del siglo XIV y los inicios del siglo $\mathrm{XV}$, en que la titularidad señorial fue más o menos inestable y cambiante, ésta terminaría por consolidarse en manos de un linaje del grupo altonobiliario más prominente del reino

5 Véase a este respecto, entre otros, RUIZ DE LA PEÑA, J. I., "Los procesos tardíos de repoblación urbana en las tierras del norte del Duero (s. XII-XIV)", Boletín del Real Instituto de Estudios Asturianos, 30, 1976, pp. 735-778; GARCÍA DE CORTÁZAR, J. Á., et ALII, Organización social del espacio en la España medieval. La Corona de Castilla en los siglos VII a XV, Barcelona, 1985; RUIZ DE LA PEÑA, J. I., "El desarrollo urbano de la periferia norteña castellano-leonesa en la Edad Media (siglos XII-XIV)", Anuario de Estudios Medievales, 19, 1989, pp. 169-186; MARTÍNEZ SOPENA, P., "El despliegue urbano en los reinos de León y Castilla durante el siglo XII”, en III Semana de Estudios Medievales (Nájera, 1992), Logroño, 1993, pp. 27-41; IDEM, "Repoblaciones interiores, villas nuevas de los siglos XII y XIII", en Despoblación y repoblación del valle del Duero, siglos VIII-XX (IV Congreso de Estudios Medievales, Fundación Sánchez-Albornoz, 1993), León, 1995, pp. 163-187; MONSALVO ANTÓN, J. Mª., "Los territorios de las villas reales de la Vieja Castilla, ss. XI-XIV: antecedentes, génesis y evolución (Estudio a partir de una docena de sistemas concejiles entre el Arlanza y el Alto Ebro)", Studia Historica. Historia Medieval, 17, 1999, pp. 15-86; GARCÍA DE CORTÁZAR, J. A. (ed.), Del Cantábrico al Duero. Trece estudios sobre organización social del espacio en los siglos VIII al XIII, Santander, 1999; y los artículos de este mismo autor, "Organización social del espacio: Propuestas de reflexión y análisis histórico de sus unidades en la España medieval", y "Organización del espacio, organización del poder entre el Cantábrico y el Duero en los siglos VIII a XIII”, recopilados en GARCÍA DE CORTÁZAR, J. A., Sociedad y organización del espacio en la España medieval, Granada, 2004, pp. 59-136 y 137-179, respectivamente.

6 Así se deduce sobre la base de tres documentos distintos. Por un lado, la confirmación por Sancho IV de Castilla en 1286 del deslinde de términos de Peñafiel, que remite a una primera señalización de los mismos por Alfonso VIII unos años antes, en 1191 [GAIBROIS DE BALLESTEROS, M., Historia del reinado de Sancho IV de Castilla, Tomo III, Madrid, 1922, p. LXXXVII, documento (doc.) 140]. Por otro, la sentencia en que Alfonso VIII de Castilla dirimió los pleitos entre Peñafiel y la vecina villa de Cuéllar, deslindando los confines entre una y otra en 1207 [Archivo Histórico Nacional (AHN), Nobleza, Priego, carpeta (carp.) 318, nº 8; GONZÁLEZ, JULIO, El reino de Castilla en la época de Alfonso VIII. Tomo III. Documentos, 1191-1217, Madrid, 1960, pp. 430-433], señalados ya completamente para Cuéllar en 1210 en su pleito con Aguilafuente (GONZÁLEZ, J., op. cit., pp. 770-773). Finalmente, la posterior confirmación de Fernando III de los límites y amojonamientos dictados por Alfonso VIII, en 1219, según noticia archivística del siglo XVII de este documento, hoy desaparecido, que hubo de conservar el concejo de Peñafiel [Archivo Histórico Provincial de Valladolid (AHPV), Documentación concejil, S.H. 00-17], sólo unos años posterior, apunta hacia la persistencia del antagonismo entre Cuéllar y Peñafiel por este motivo.

7 MARTÍNEZ DÍAZ, G., op. cit., pp. 9-47 y, más en concreto sobre Peñafiel, pp. 389-392. La documentación manejada por este autor permite fijar este censo como preciso para mediados del siglo XIII. 
en pleno siglo $\mathrm{XV}^{8}$. Ya Alfonso VIII y Fernando III donaron Peñafiel a sus respectivas esposas y, en 1283, Sancho IV la entregaría a su tío, el infante don Manuel, de quien la heredaría el famoso don Juan Manuel, destacado benefactor de esta población vallisoletana9. A través de su hija, Juana Manuel, esposa de Enrique II, la villa volvería al patrimonio regio para, de nuevo, ser señorío de reinas y de infantes. Convertida en ducado en manos del infante Fernando de Antequera, luego rey de Aragón, pasaría a su hijo, el infante don Juan de Aragón, rey de Navarra desde 1425 y, tras los enfrentamientos civiles ocurridos en Castilla durante el reinado de Juan II y los diversos cambios de titularidad de la villa — además de los diferentes desgajamientos y reintegraciones de aldeas hasta 1470_, en 1446 ingresaría finalmente dentro de los estados de don Pedro Girón, maestre de Calatrava, origen de los Téllez Girón y de la Casa de Osuna, dentro de los cuales permanecería hasta el final del Antiguo Régimen ${ }^{10}$.

La relevancia de Peñafiel en los siglos finales de la Edad Media podría quedar puesta de manifiesto exclusivamente a causa del interés en ella de los más destacados personajes del reino, como hemos podido observar. No obstante, es para los siglos XIV y XV cuando ya contamos con algunos datos más ilustrativos sobre su potencial demográfico. Hasta donde sabemos, Peñafiel era una próspera villa amurallada ${ }^{11}$, que a mediados del siglo XIV contaba con doce parroquias, además de habitar en ella una apreciable comunidad hebrea $^{12}$. Posiblemente ya en esa época, la de don Juan Manuel, estuviera dotada de una poderosa fortaleza en lo alto de loma que domina el poblado, la cual precedió a la posteriormente erigida por los Téllez Girón y que hoy podemos contemplar ${ }^{13}$. Conocemos por

8 MONSALVO ANTÓN, J. M"., "Las dos escalas de la señorialización nobiliaria al sur del Duero: concejos de villa-y-tierra frente a señorialización "menor" (estudio a partir de casos del sector occidental: señoríos abulenses y salmantinos", Revista d'Història medieval, 8, 1997, pp. 275-338, en concreto pp. 275-296. Aunque el análisis se aplica sobre el área occidental de la "Extremadura", el propio autor la extrapola al conjunto de esta zona a resultas de la bibliografía disponible de un modo, como viene a corroborar el caso de Peñafiel, bien fundado.

9 Don Juan Manuel tuvo por predilecta a Peñafiel entre sus vastos señoríos. En ella residió varios años y escribió algunas de sus obras, interviniendo decisivamente en su ordenamiento municipal y fundando el convento de dominicos en el cual sería enterrado. Véase MARTíN, J.-L., "Don Juan Manuel. Fundador del convento de San Juan y San Pablo de Peñafiel”; y VALDEÓN BARUQUE, J., "Don Juan Manuel y Peñafiel”, en Don Juan Manuel. VII Centenario, Murcia, 1982, pp. 177-185 y 385-395, respectivamente.

10 Sobre los diferentes señores de Peñafiel entre 1188 y los inicios del siglos XVI, ESCRIBANO DE LA TORRE, F., Peñafiel. Notas históricas, Valladolid, 1977 (2ª ed.), pp. 165-225; GARCÍA GARCÍA, E., San Juan y San Pablo de Peñafiel. Economía y sociedad de un convento dominico castellano (1318-1512), Valladolid, 1986, pp. 36-39; MARTÍNEZ LLORENTE, F. J., op. cit., pp. 314-332; AGUADO GONZÁLEZ, F. J., El ascenso de un linaje castellano en la segunda mitad del siglo XV: los Téllez Girón, condes de Ureña (El origen del señorío de Osuna), Madrid, 1990, pp. 197-198.

11 Según el Cronicón de don Juan Manuel, en 1345, este señor comenzó a reedificar los muros de Peñafiel, ESCRIBANO DE LA TORRE, F., op. cit., pp. 264-267.

12 Sobre las parroquias peñafielenses, MARTÍNEZ DÍEZ, G., op. cit., pp. 392. En lo que toca a la aljama de Peñafiel, ésta sólo se documenta con mayor certidumbre a partir de los registros fiscales de la Corona de la época de los Reyes Católicos (AGUADO GONZÁLEZ, F. J., op. cit., pp. 863-867, citando a SUÁREZ FERNÁNDEZ, L., Documentos acerca de la expulsión de los judios, Valladolid, 1964).

13 Respecto al castillo de Peñafiel, su evolución y las dificultades en la datación de sus fases constructivas, BLANCO SANCHO, R., "El castillo de Peñafiel”, Castillos de España, 136, 2005, pp. 55-59; SANTIAGO PARDO, J. de, y VILLANUEVA ZUBIZARRETA, O., "Nuevas del castillo de Peñafiel tras su primera excavación", en I Simposium de Arqueología Medieval. Homenaje al Prof. Manuel Riu (en prensa). 
una referencia de 1490 relativa a la recaudación del impuesto de la martiniega de la villa y tierra - que se pagaba al convento dominico de San Juan y San Pablo de la villa - que en esos años Peñafiel ejercía jurisdicción sobre un total de quince aldeas (Quintanilla de Arriba, Quintanilla de Abajo, Langayo, San Mamés, Mélida, Olmos, Castrillo, Rábano, La Torre, Canalejas, Fompedraza, Molpeceres, Manzanillo, Padilla y Molpeceres de Ayuso). Otros lugares se habían despoblado para esas fechas, siendo el último de ellos en quedar yermo el de Carrascal. A su vez, Pesquera, que había sido también aldea de Peñafiel, era ahora una villa autónoma ${ }^{14}$. Por otra parte, la población del conjunto de la villa y tierra de Peñafiel era tasada en 1439 en 1.200 vasallos, a partir de la que podríamos extrapolar, teniendo en cuenta las característica de la fuente y el tipo de referencia, en torno a unos 5.000-7.000 habitantes para los años centrales del siglo XV; en cualquier caso, no resulta posible proponer qué porcentaje de habitantes correspondería a la villa y cuál a las aldeas ${ }^{15}$.

\section{EL CONCEJO DE PEÑAFIEL. EVOLUCIÓN INSTITUCIONAL Y DINÁMICA SOCIOPOLÍTICA}

Nuestras primeras noticias sobre el concejo de Peñafiel se refieren a dos textos forales: el llamado "fuero apócrifo" de Peñafiel, un falso que habría de datarse en el siglo XII, basado en el fuero latino de Sepúlveda" ${ }^{16}$, en el momento de organización de la "Extremadura castellana", y el fuero concedido por el rey Fernando III a la villa en $1222^{17}$. Éste refería al "fuero apócrifo" como anterior cuerpo legal en vigor de Peñafiel, viniendo a completarlo en un momento en que la monarquía castellano-leonesa inició sus esfuerzos para uniformizar los ordenamientos jurídicos de las villas extremaduranas y establecer un control sobre la autonomía de estos concejos, una vez que la "Extremadura castellanoleonesa" perdía su calidad de frontera frente a territorios musulmanes con el avance de la conquista hacia Andalucía ${ }^{18}$.

14 AHN, Códices, libro 1.264, pp. 275-279, y AHN, Clero, Papeles, legajo (leg.) 7.635, nº 7. Pesquera, como decíamos, había sido donada en 1395 por el infante Fernando de Antequera, duque de Peñafiel, al Justicia Mayor del Rey, Diego López de Stúñiga (AHN, Nobleza, Osuna, carpeta 42, nº. 3).

15 En la cédula de Juan II de Castilla en que se aprobaba la renuncia del rey de Navarra a sus señoríos castellanos en 1440, se insertaba la donación que en 1439, en pleno contexto de agitación interna en el reino, Juan II había hecho de éstos lugares a diferentes señores, tasándose el número de vasallos de, entre otros dominios, la villa y tierra de Peñafiel (AHN, Nobleza, Frías, Ca . 292, nº. 9-13). Teniendo en cuenta que, en esos años, las aldeas de Quintanilla de Arriba y Quintanilla de Abajo habían sido enajenadas y no volverían a reintegrarse a la jurisdicción de Peñafiel hasta 1470 (AGUADO GONZÁLEZ, F. J., op. cit., pp. 197-198), y las propias dificultades que plantea el término "vasallo" a la hora de remitir a un elemento cuantificable para el cálculo demográfico, si aplicamos estas correcciones la multiplicación de la cifra por unos coeficientes razonables para el cálculo de la ratio de personas por familia (4-5) y consideramos los posibles segmentos de población no incluidos en nuestra referencia, no resulta descabellado el cálculo de población que proponemos para el conjunto de Peñafiel y su tierra a mediados del siglo XV.

16 RUIZ ASENCIO, J. M., "La provincia de Valladolid en la Alta Edad Media (S. VIII-XI)", en Valladolid Medieval, Valladolid, 1980, pp. 9-63.

17 GONZÁLEZ DÍEZ, E., op. cit., pp. 14-15 y 55-56.

18 MARTÍNEZ LLORENTE, F. J., op. cit., pp. 200-236. 
Estas normativas no difieren en general de otras de esta época: nos colocan ante la existencia del "concejo abierto", configurado por la reunión del conjunto de los vecinos para la deliberación y toma de decisiones de interés común a toda la villa y tierra, pero en el que se aprecian dos preeminencias claras. Por un lado, la de los habitantes de la villa sobre los de las aldeas, al quedar excluidos éstos de la participación en el gobierno, y, por otro lado, la de los guerreros, aquellos que mantienen caballo y armas, los "caballeros villanos", como elite social de estas villas de la "Extremadura", constituida al calor de la actividad militar de la frontera con el Islam ${ }^{19}$. Ellos, tal y como expone el fuero de Fernando III, son los únicos que podían ser elegidos para ocupar los oficios concejiles. De estos oficios sólo sabemos que habrían de reelegirse anualmente, de entre los caballeros, no habiendo lugar a que un individuo pudiera ser reelegido antes de que todos aquellos que estuvieran capacitados para ejercer un oficio concejil lo hubieran ocupado, y que las elecciones debían ser notificadas al rey para su confirmación. Mientras, para la recaudación de los impuestos reales, se establecía que dos representantes de cada collación de la villa y de cada cuarto de la tierra, o sea, por cada una de las circunscripciones internas en que se dividían respectivamente villa y tierra, serían elegidos para acometerla junto a los oficiales del rey, si bien no se concretaba la calidad social de estos hombres buenos, como son llamados en el fuero ${ }^{20}$.

No nos detendremos aquí a analizar las concesiones del Fuero Real en 1256 y del Privilegio de la "Extremadura" en 1264 a Peñafiel, ya que no venían a modificar fundamentalmente la estructura del concejo y, en último término, el descontento general del reino contra las reformas del Rey Sabio, que terminó desembocando en la rebelión contra él de la nobleza y las ciudades encabezada por su propio hijo, el infante don Sancho, luego Sancho IV, conducirían a que la efectividad de estos ordenamientos fuera relativamente efímera. Magníficamente estudiados por otros autores, serían el máximo exponente de la política alfonsí de intento de normalización jurídica de los reinos de Castilla y León en una posición de superioridad legislativa de la autoridad regia, por una parte, además de ahondar en el proceso de diferenciación social de la elite de caballeros y escuderos de villas y ciudades del resto de la población mediante la concesión de privilegios y exenciones ${ }^{21}$.

Este segundo aspecto es si cabe mucho más relevante para nuestro relato, ya que la turbulenta época que va del final del reinado de Alfonso X a la mayoría de edad de Alfonso XI, grosso modo del final del siglo XIII a mediados del siglo XIV, correspondería, en el ámbito de las villas y ciudades de Castilla, con una dinámica de pugna alrededor de la participación y ejercicio del poder municipal al socaire de los procesos de aristocratización u oligarquización de las instancias políticas urbanas. Es decir, de choques motivados por el afán del grupo de los caballeros por distinguirse social y políticamente del resto de la población. Por un lado, como parte del grupo social de la nobleza, aún en su rango

19 Esta es una tónica general en el espacio de la "Extremadura castellano-leonesa", de decantación de una jerarquía social dominada por los "caballeros villanos", en los concejos, y por los clérigos a través de los cabildos eclesiásticos de catedrales y villas entre los siglos XI y XIII. VILLAR GARCÍA, L. M., op. cit., pp. 532-554.

20 Además de todo esto, aunque se cita que el concejo podía poner aportellados y adelantados, nada se indica sobre los oficiales principales del concejo: alcaldes, encargados de la justicia, merinos o alguaciles encargados de ejecutar las sentencias de los alcaldes, etc. GONZÁLEZ DÍEZ, E., op. cit., pp. 55-56.

21 Ver nota anterior, MARTÍNEZ LLORENTE, F. J., op. cit., pp. 237-261. 
más inferior, argumentada sobre el ejercicio de la función armada de caballeros; por el otro, y sobre la base de esa diferencia funcional pero sobre todo socio-económica, como únicos individuos capaces de ejercer el gobierno de las ciudades. Estos enfrentamientos, en último término, devendrían en la instauración del "regimiento", de un concejo formado por un número cerrado de individuos, del que quedaba excluida la participación del conjunto de la población, si bien la forma en que se resolvieron fue muy dispar en cada villa y ciudad, jugando en ella un papel clave la intervención del Rey o de los señores jurisdiccionales de esos lugares ${ }^{22}$. Es justamente en ese caldo de cultivo en el que ha de entenderse la promulgación de las ordenanzas de 1345 por don Juan Manuel, señor de Peñafiel ${ }^{23}$.

Una atenta lectura de las mismas permite comprobar cómo son el resultado de un acuerdo para superar una situación previa de conflicto que enfrentaba a los caballeros y al resto de la población de la villa, pero en el cual el señor también se había visto implica$\mathrm{do}^{24}$. Ciertamente, don Juan Manuel prohibió la convocatoria del "concejo abierto", limitándolo a tan sólo un "regimiento" de seis personas, seis hombres buenos, invocando el mal que suponía que en cada reunión del concejo cualquier persona de pequeña fazienda hablase como quisiera y deshiciese los acuerdos de estos caballeros y hombres buenos ${ }^{25}$. Además, entregó los oficios de las alcaldías y el alguacilazgo, encargados del ejercicio de la justicia y de la ejecución de las leyes y las sentencias impuestas por las personas competentes para ello, respectivamente, a los caballeros ${ }^{26}$. No obstante, el poder de éstos quedaba contrapesado con diferentes medidas que tenían en cuenta el peso político local de aquellos que no eran caballeros. Así, los seis oficios del regimiento habrían de repartirse, cuatro para los caballeros y dos para los hombres buenos de la villa, término que ya se refiere a los más prominentes miembros de aquellos que no eran caballeros y, por tanto, pechaban, pagaban impuestos. Más aún, las seis regidurías no eran vitalicias, sino que habían de ser elegidas anualmente ${ }^{27}$.

Por ello, aunque don Juan Manuel había otorgado a los caballeros privilegios y exenciones y, de hecho, les reservaba la mayoría de los oficios, su posición de poder quedaba

22 CASADO ALONSO, H., "Las relaciones poder real-ciudades en Castilla en la primera mitad del siglo XIV"; RUCQUOI, A., "Pouvoir royal et oligarchies urbaines d'Alfonso X à Fernando IV de Castille", en RUCQUOI, A. (coord.), Génesis medieval del Estado Moderno. Castilla y Navarra (1350-1370), Valladolid, 1987, pp. 173-192 y 193-216, respectivamente. Sobre el asunto de la mediación regia o señorial en estos conflictos urbanos surgidos durante el establecimiento del "regimiento", JARA FUENTE, J. A., "Estructuras formales de poder y de organización de las clases dominante urbanas en Castilla. El regimiento: una crisis del siglo XIV en el siglo XV”, Edad Media. Revista de Historia, 8, 2007, pp. 225-241.

23 Ver nota 3.

24 Se cita en la ordenanza 77, sobre el pago de salario de las alcaldías, a los alcaldes ...que ffueron ante que les tomassemos los offiçios. (KINKADE, R., op. cit., pp. 61). Si los oficios concejiles correspondían a los "caballeros villanos" según el fuero de Fernando III, todo apunta a que el señor, en algún momento, había decidido incautarles el nombramiento de las alcaldías y, en general, de todos los oficios. El preámbulo de las ordenanzas también refiere cómo don Juan Manuel tomó para sí las alcaldías y el alguacilazgo, devolviéndolas ahora a los caballeros ...que tomaron las mjs cauallerias Assi commo lo ssolian Auer (Ibidem, pp. 35-36).

$\mathrm{Al}$ ordenar sobre, don Juan Manuel señala que se paguen de las rentas del concejo, tal y como lo hacían hasta entonces los alcaldes

25 Ibidem, p. 36, ordenanza $\mathrm{n}^{\circ} .2$.

26 Ibidem, pp. 35-36, señalado en el preámbulo.

27 Ibidem, pp. 36-37, ordenanzas n ${ }^{\circ} .2$ y 4. 
fuertemente limitada en varios aspectos. Primero, por la participación de la elite pechera en la administración del concejo. En segundo lugar, esta mediatización se extendía en materia fiscal a los líderes de las aldeas de la tierra, que podrían participar en las decisiones que afectaran a los repartimientos de pechos junto con los distintos oficiales del concejo $^{28}$. Por si fuera poco, la supervisión sobre los caballeros también era ejercida por el propio señor en la medida en que, como explícitamente se indica en las ordenanzas, don Juan Manuel había regulado el ejercicio de su función de caballeros por otra su ordenanza que no se nos ha conservado, presumiblemente poniéndolos a su servicio como vasallos armados que percibían acostamientos pagados por la hacienda señorial, quedando de este modo ligados a él ${ }^{29}$. Un sistema, pues, que parece dirigido a crear una situación de gobierno estable sobre Peñafiel manteniendo un equilibrio entre los intereses de las diferente fuerzas sociales de la villa y tierra, supervisado y garantizado por la autoridad señorial y que, en definitiva, beneficiaba el ejercicio de esta última sobre la villa.

Estas ordenanzas serían la base del ordenamiento jurídico de Peñafiel hasta el inicio del siglo XVI y, de hecho, durante toda la Edad Moderna, adecuándose y completándose en lo que tocaba a la organización concejil en los capítulos que no aparecían desarrollados en ella. Éstos son bastante reseñables y, precisamente, serían motivos de posteriores disturbios entre caballeros y pecheros hasta muy avanzado el siglo $\mathrm{XVI}^{30}$, puesto que el antagonismo entre ambos sectores no desaparecieron. La perspectiva que nos ofrece la documentación de la segunda mitad del siglo XIV y de el siglo XV es de acentuación de los mismos ante el aumento del empuje de la capa más elevada social y económicamente de los pecheros para mantener su participación en el gobierno de la villa o ampliarla frente al afán de las familias de caballeros por distinguirse como una elite social bien definida, la de hijosdalgos miembros de la nobleza, con derecho exclusivo a ejercer el dominio del concejo frente a los pecheros, cerrada a advenedizos enriquecidos que pretendieran integrarse en ella ${ }^{31}$.

Concretemos, en cualquier caso, cómo quedó configurado el concejo de Peñafiel en la Baja Edad Media. Las fuentes posteriores a 1345 nos informan sobre el resto del

28 Ibidem, pp. 36-37, ordenanza $\mathrm{n}^{\circ} .5$.

29 Ver nota 23.

30 El último pleito importante entre los caballeros y pecheros de Peñafiel en torno a los sistemas de elección y representación del concejo de la villa data de 1566, librándose definitivamente en 1582 en contra de las pretensiones monopolísticas del ayuntamiento de caballeros (AHPV, Documentación concejil, S.H., 331, 12).

31 La problemática sobre la dialéctica por participación política en los concejos castellanos bajomedievales es de una notable complejidad a la hora de distinguir a sus distintos protagonistas, los intereses individuales y de grupo en juego, las estrategias desarrolladas por los actores en litigio, el papel jugado por los poderes jurisdiccionales superiores -Corona y señores- ante estas oposiciones, etc. Para un acercamiento a este universo, remitimos, entre otros, a los trabajos de MONSALVO ANTÓN, J. Ma ., "La participación política de los pecheros en los municipios castellanos de la baja Edad Media. Aspectos organizativos", Studia Historica. Historia medieval, 7 , 1989, p. 37-93; VAL VALDIVIESO, Ma . I. del, “Aspiraciones y actitudes socio-políticas. Una aproximación a la sociedad urbana de la Castilla bajomedieval”, en BONACHÍA HERNANDO, J. A. (coord.), La ciudad medieval. Aspectos de la vida urbana en la Castilla bajomedieval, Valladolid, 1996, pp. 213-254; MARTÍN CEA, J. C., BONACHÍA HERNANDO, J. A., "Oligarquías y poderes concejiles en la Castilla bajomedieval. Balance y perspectivas", Revista d'Història Medieval, 9, 1998, 17-40 (especialmente 33-35); JARA FUENTE, J. A., "Sobre el concejo cerrado, Asamblearismo y participación política en las ciudades castellanas de la Baja Edad Media (conflictos inter o intra-clase)", Studia Historica. Historia Medieval, 17, 1999, 113-136. 
organigrama concejil que no era citado en las ordenanzas, bien porque ya existiera previamente y, al ser bien conocido en la villa no fuera necesario explicitarlo en el texto, bien porque terminara de constituirse en estos años. En efecto, el compendio de oficiales del concejo aparece perfectamente comprendido entre 1425-1443, tal y como nos muestran el conjunto de ordenanzas expedidas por don Juan, rey de Navarra, a resultas de un nuevo conflicto que enfrentó a caballeros y pecheros de Peñafiel, ante la pretensión por parte de los primeros de copar la totalidad de los cargos de la administración municipal ${ }^{32}$. El cuadro sería el siguiente:

- 6 regidores, 4 de ellos caballeros y 2 pecheros.

- 2 alcaldes, uno de ellos caballero y el otro pechero.

- 1 alguacil, correspondiente a los caballeros.

- 1 mayordomo, encargado de las finanzas públicas, pechero.

- 1 escribano de concejo, que pasaría a ser nombrado por el señor libremente.

- 4 fieles, arrendadores de las rentas del concejo, la mitad caballeros y la mitad pecheros.

En términos generales, la ordenanza definitiva de Juan de Navarra estableció que todos los oficios debían repartirse por mitades entre pecheros y caballeros. Como se puede ver, esta división por mitades afectó a todos los cargos, incluidos otros de carácter menor que no hemos citado, como los encargados de guardar las llaves del arca en que se guardaban los documentos del concejo, el sello concejil y las llaves de las puertas de la villa, pero sin modificar los estatutos explicitados en la ordenanza de don Juan Manuel, por ejemplo, relativos a los "regimientos".

La complejidad de la organización concejil alcanzada en Peñafiel antes de mediados del siglo XV no queda aquí. En el litigio librado en torno a estas ordenanzas puede observarse como tanto caballeros como pecheros habían tendido a adquirir unas identidades de grupo altamente perfiladas, constituyéndose en ayuntamientos separados e institucionalizados, lo que señala un alto nivel de sofisticación en la canalización de la participación política ${ }^{33}$. Pero ya antes, al menos en 1402, encontramos que la representación del conjunto de la comunidad de la villa y tierra era ejercida a través de procuradores del pueblo, uno por la villa y dos por las aldeas de la tierra, una muestra de que los intereses del conjunto de los pecheros de la villa y tierra, sobre todo de las comunidades de las aldeas, acaso no eran tan coincidentes con los de los hombres buenos pecheros de Peñafiel y habían adquirido una voz propia en las instituciones concejiles ${ }^{34}$.

32 Las mismas han sido publicadas y brevemente analizadas en sintonía a esta preocupación por la conflictividad en el seno de la sociedad urbana castellana del siglo XV, a partir de una copia tardía de época moderna, por MIRANDA GARCÍA, F., "Conflictos sociales y poder concejil en una villa de señorío. Peñafiel (14251443)", Historia. Instituciones. Documentos, 33, 2006, pp. 435-456. El original, en cualquier caso, se conserva entre los restos salvados de los instrumentos antiguos del archivo municipal en el Archivo Histórico Provincial de Valladolid (AHPV, Documentación concejil, S.H. 331, 11).

33 Así lo evidencian las reuniones de estos ayuntamientos en la primavera de 1443 para nombrar delegados que presentasen su alegaciones ante Juan de Navarra (AHPV, Documentación concejil, S.H. 331, 11, ff. 1 r.-3 v. y 5 r. -6 r.).

34 En reunión del concejo de Peñafiel de 6 de enero de 1402 para levantar acta sobre el juicio que les enfrentaba con la vecina villa de Cuéllar por los términos comunales que compartían y que iba a dirimir el juez delegado por el señor de ambas villas, el infante Fernando de Antequera, aparece la cita a ... Pero Ferrández. 
El marco de cargos concejiles quedaría completado con las escribanías de la villa, siete en total, entre ellas la que ejercía la escribanía del concejo. Según la ordenanza de 1443 que despachó el conflicto del que hemos venido hablando, éstas quedaron reservadas por el rey de Navarra para su libre nombramiento por el señor ${ }^{35}$. Esta decisión sería, a su vez, una muestra de la progresiva intromisión que la autoridad señorial tendió a ejercer sobre el gobierno municipal de Peñafiel a lo largo la segunda mitad del siglo XIV y, sobre todo, del siglo XV; una realidad, por otro lado, no muy diferente de la vivida en otros lugares de señorío de toda la Corona de Castilla. Ésta se manifestaría a través de toda una panoplia de medidas que buscaban hacer más presente la autoridad señorial sobre los asuntos de la vida pública de sus dominios, particularmente escenificada mediante la introducción, primero temporal en época de los señoríos de reinas e infantes de la Casa real de Castilla, y luego permanente, ya bajo el señorío de los Téllez Girón, del corregidor o alcalde mayor como su delegado personal en el concejo y oficial supremo del mismo ${ }^{36}$.

El aparato concejil de la villa y tierra de Peñafiel, a razón de lo que se deduce de la documentación del final del siglo XV y del siglo XVI, no parece que sufriera grandes modificaciones una vez alcanzada, en la década de 1440, una estructura cuya evolución hemos tratado de presentar ${ }^{37}$. Un caso, el de Peñafiel, ejemplificante, dentro de su carácter original y genuino, fruto de la propia trayectoria histórica de la villa, de la complejidad y sutileza alcanzado, en términos de gobierno y participación social en la vida política, por los sistemas de organización municipal-territorial de la Corona de Castilla a lo largo

de la Edad Media.

Çerralvo, procurador del pueblo de la dicha villa, e Juan Gonçález e Pero Gonçález, procuradores de los pueblos de las aldeas de la villa... [UBIETO ARTETA, A. (ed.), Colección Diplomática de Cuéllar, Segovia, 1961, doc. 159, pp. 319-322]. No obstante, en 1366 y 1386 se cita, en la documentación del convento de San Juan y San Pablo al guarda de los pueblos de la tierra de Peñafiel, o guarda y procurador de los pueblos, cuyo nombramiento, por privilegio de don Juan Manuel, correspondía a los frailes dominicos de este convento [Biblioteca Universitaria de Oviedo (BOU), Documentos en Papel I, Ca. 6, nº. 2 y n ${ }^{\circ}$ 16]. Que en 1402 se citen ya dos procuradores de los pueblos de las aldeas sugiere que acaso el cargo se duplicó para guardar el derecho del convento pero poder así contar las aldeas de la tierra con un representante propio elegido por ellos.

35 AHPV, Documentación concejil, S.H. 331, 11, ff. 11 v. y ss.). A partir de una referencia del cartulario del convento de San Juan y San Pablo conocemos el número de escribanías, ya que los frailes poseían un foro sobre los derechos de las mismas, y el nombre de los escribanos en el momento de elaboración del cartulario (AHN, Códices, Libro $n^{\circ}$. 1.264, pp. 443-446).

36 La introducción del corregidor encaja dentro de las estrategias de construcción del poder señorial en la Castilla bajomedieval. Véase, en general y sobre el caso de Peñafiel, Calderón Ortega, José Manuel, "Los corregidores del duque de Alba (1430-1531), Anuario de la Facultad de Derecho de Alcalá de Henares, 3, 19931994, pp. 107-134; MUÑOZ GÓMEZ, V., "Administración señorial y gobierno urbano durante los primeros Trastámara. Los corregidores del infante Fernando de Antequera y Leonor de Alburquerque (1392-1421)", en JIMÉNEZ ALCÁZAR, J. F., MAÍZ CHACÓN, J., VILLANUEVA MORTE, C. y CALDERÓN MEDINA, I. (eds. científicos), Actas IV Simposio Internacional de Jóvenes Medievalistas. Lorca 2008, Murcia, 2010, pp. 161-185; AGUADO GONZÁLEZ, F. J., op. cit., pp. 495-496 y 538-540.

37 Así lo evidencia la sentencia del pleito de 1582, que no modificó las ordenanzas preexistentes de la villa sino que completó aspectos no comprendidos en ella, como los tocantes a la posible reelección de un individuo para oficios concejiles (ver nota 30). 